\title{
PENGARUH TERAPI PIJAT REFLEKSI KAKI TERHADAP TEKANAN DARAH PADA PENDERITA HIPERTENSI PRIMER
}

\author{
STIKES Aisyiyah Surakarta \\ Sri Hartutik, Kanthi Suratih \\ Ners_Tutty@yahoo.com
}

\begin{abstract}
ABSTRAK
Hipertensi atau penyakit tekanan darah tinggi merupakan suatu gangguan pada pembuluh darah yang mengakibatkan penurunan suplai oksigen dan nutrisi.Penyakit ini menjadi salah satu masalah utama dalam dunia kesehatan masyarakat di Indonesia maupun dunia. Menurut catatan Badan Kesehatan Dunia WHO 2011 ada 1 milyar orang didunia menderita hipertensi dan 2/3 di antaranya berada dinegara berkembang. Diperkirakan sekitar $80 \%$ kenaikan kasus hipertensi terutama terjadi di negara berkembang pada tahun 2025 dari Jumlah total 639 juta di tahun 2000. Jumlah ini diperkirakan meningkat menjadi 1,15 miliar kasus ditahun 2025.Penelitian ini menggunakan metode Quasy Eskperiment dengan desain penelitian yang digunakan adalah pre-postest control one group designPopulasi pada penelitian ini adalah lansia yang tinggal di Panti Wredha Pajang Surakarta sebanyak 74 orang. Sampel dalam penelitian ini sejumlah 11 orang untuk masing-masing kelompok intervensi dan kelompok kontrol, sehingga jumlah keseluruhan sampel adalah 22 responden.

Hasil penelitian menunjukkanuji Mann Whitney untuk pengaruh terapi pijat refleksi kaki terhadap tekanan darah pada penderita hipertensi primer sesudah diberikan perlakuan (post test) p value $(0,000<0,05)$ ada perbedaan tekanan darah pada kelompok perlakuan dan kelompok kontrol sesudah diberikan perlakuan terapi pijat refleksi kaki.

Terapi pijat refleksi sebagai salah satu terapi komplementer diharapkan mampu untukdiaplikasikan perawat dalam menurunkan tekanan darah pada penderita hipertensi.
\end{abstract}

Kata kunci: pijat refleksi kaki, hipertensi

\section{ABSTRACT}

Hypertension or high blood pressure disease is a disorder of the blood vessels resulting in decreased oxygen supply and nutrients. This disease becomes one of the main problems in the world of public health in Indonesia and the world. According to World Health Organization WHO 2011 records there are 1 billion people in the world suffering from hypertension and 2/3 are in developing countries. An estimated $80 \%$ rise in hypertension cases occurs mainly in developing countries by 2025 from a total of 639 million in 2000. This number is estimated to increase to 1.15 billion cases by 2025. This study uses the Quasy Eskperiment method with pre- -postest control one group design The population in this study is elderly living in Panti Wredha Pajang 
Surakarta as many as 74 people. The sample in this study is 11 people for each intervention group and control group, so the total sample is 22 respondents.

The results showed that Mann Whitney test for the influence of foot reflexology therapy on blood pressure in patients with primary hypertension after treatment (post test) $p$ value $(0,000<0,05)$ there was difference of blood pressure in treatment group and control group after treatment of foot reflection therapy.

Reflexology therapy as one of the complementary therapies is expected to be applied by nurses in lowering blood pressure in hypertensive patients.

Keywords: foot reflexology massage, hypertension

\section{A. PENDAHULUAN}

Hipertensi adalah dimana tekanan darah yang bersifat abnormal dan diukur paling tidak pada tiga kesempatan yang berbeda. Apabila seseorang dianggap mengalami hipertensi dimana tekanan darahnya lebih dari 140/90 mmhg (Ardiansyah,2012).

Hipertensi atau penyakittekanan darahtinggi merupakan suatu gangguan padapembuluh darah yang mengakibatkanpenurunan suplai oksigen dan nutrisi(Pudiastuti, 2013). Penyakit ini menjadi salah satu masalah utama dalam dunia kesehatan masyarakat di Indonesia maupun dunia. Menurut catatan Badan Kesehatan Dunia WHO 2011 ada 1 milyar orang didunia menderita hipertensi dan $2 / 3$ di anataranya berada dinegara berkembang. Diperkirakan sekitar 80\% kenaikan kasus hipertensi terutama terjadi di negara berkembang pada tahun 2025 dari Jumlah total
639 juta di tahun 2000. Jumlah ini diperkirakan meningkat menjadi 1,15 miliar kasus ditahun 2025.(Ardiansyah ,2012).

Dalam penelitian yang dilakukan oleh Anwar R (2014) sepertiga dari populasi orang dewasa di Asia Tenggara termasuk Indonesia memiliki tekanan darah tinggi. Hipertensi penyebab kematian nomor 3 setelah stroke dan tuberkulosis, yakni mencapai 6,7\% dari populasi kematian pada semua umur di Indonesia. Prevalensi hipertensi di Indonesia mencapai $31,7 \%$ dari populasi usia 18 tahun keatas. Dari jumlah itu, 60\% penderita hipertensi mengalami komplikasi stroke. Sedang sisanya mengalami penyakit ginjal, gagal ginjal, dan kebutaan. (Triyanto,2014).

Menurut Riskesdas (2013), prevalensi hipertensi di Indonesia adalah sebesar 25,8\%. Berdasarkan data dinas kesehatan provinsi jawa tengah (2015) prevalensi hipertensi 


\section{GASTER Vol. XV No. 2 Agustus 2017}

disurakarta adalah sebesar 18,47\%. Untuk jumlah hipertensi ensensial disurakarta tahun 2014 adalah 62.252 kasus (provil kesehatan provinsi jawa tengah tahun, 2015)

Hipertensi dapat dibedakan menjadidua kelompok, yaitu hipertensi primer dansekunder. 90\% dari semua kasus hipertensiadalah primer. Tidak ada penyebab yang jelastentang hipertensi primer, namun adabeberapa teori yang menunjukkan bahwafaktor genetik dan perubahan hormon bisamenjadi fakor pendukung. Hipertensisekunder merupakan hipertensi yangdiakibatkan oleh penyakit tertentu (Baradero,Dayrit \& Siswadi, 2008).

Komplikasi hipertensi meningkatsetiap tahunnya. WHO pada tahun 2013, menyebutkan bahwa di dunia terdapat 17.000orang per tahun meninggal akibat penyakitkardiovaskuler dimana 9.400 orangdiantaranya disebabkan oleh komplikasi darihipertensi. Prevalensi hipertensi dunia mencapai $29.2 \%$ pada lakilaki dan $24.8 \%$ pada perempuan (WHO, 2013). Prevalensi hipertensi ini akan terus meningkat dan diprediksi pada tahun 2025 sebanyak 29 $\%$ orang dewasa di seluruh dunia menderita hipertensi (Kemenkes RI, 2013). Di Indonesia sendiri, survey Kesehatan Rumah Tangga Departemen Kesehatan RI 2013 menyebutkan sekitar $16-31 \%$ dari populasi masyaraka Indonesia di berbagai provinsi menderita hipertensi (Riskesdas RI, 2013)

Pengobatan hipertensi dapat dilakukan secara farmakologis dan non farmakologis. Pengobatan farmakologis merupakan pengobatan dengan menggunakan obatobatanyang dapat membantu menurunkan sertamenstabilkan tekanan darah. Pengobatan farmakologis memiliki efek samping yaitu dapat memperburuk keadaan penyakit atau efek fatal lainnya. Hal ini dikarenakan respon terhadap suatu jenis obat pada setiap orang berbeda. Efek samping yang mungkin timbul adalah sakit kepala, pusing, lemas dan mual (Susilo \& Wulandari, 2011).

Dalam penelitian (Finansari dkk,2014) hipertensi dan komplikasinya dapat diminimalkan dengan penatalaksanaan menggunakan farmakologi yaitu dengan minum obat secara teratur atau menggunakan non-farmaklogi yaitu kepatuhan menjalankan diet, menurunkan berat badan, rajin berolahraga, mengurangi konsumsi garam, diet rendah lemak, rendah kolestrol. Pendekatan nonfarmakologis yang dapat mengurangi hipertensi adalah akupresur, ramuan cina, terapi herbal, relaksasi nafas dalam, aroma 
terapi, terapi music klasik, meditasi dan pijat (Andri \& Sulistyarini,2015) Pengobatan non farmakologis dapat digunakan sebagai pelengkap untuk mendapatkan efek pengobatan pada saat obat anti hipertensi diberikan (Dalimartha, Purnama, Sutarina, Mahendra \& Darmawan, 2008).

Pijat refleksi adalah suatu praktik memijat titik-titik tertentu pada tangan dan kaki. Manfaat pijat refleksi untuk kesehatan sudah tidak perlu diragukan lagi. Salah satu khasiatnya yang paling populer adalah untuk mengurangi rasa sakit pada tubuh. Manfaat lainnya adalah mencegah berbagai penyakit, meningkatkan daya tahan tubuh, membantu mengatasi stress, meringankan gejala migrain, membantu penyembuhan penyakit kronis, dan mengurangi ketergantungan terhadap obatobatan (Wahyuni, 2014). Hasil penelitian ini diperkuat oleh Nugroho (2012), menunjukkan bahwa pijat refleksi kaki lebih efektif dibanding hipnoterapi dalam menurunkan tekanan darah.

Studi Pendahuluan dilakukan pada tanggal 20 Januari 2017 di Panti Wredha Pajang Surakarta. Jumlah lansia yang tinggal di Panti sebanyak 74 lansia, dengan jumlah penderita hipertensi sebanyak 27 lansia dengan tekanan darah rata-rata diatas 140/90 $\mathrm{mmHg}$. Melalui wawancara terhadap 15 orang penderita hipertensi mengatakan mengalami pusing. Hasil wawancara menunjukkan bahwa 8 orang penderita hipertensi belum mengetahui pijat refleksi dapat menurunkan tekanan darah, dan sisanya pernah melakukan pijat refleksi lalu kemudian berhenti. Berdasarkan penjelasan di atas, peneliti ingin mengetahui apakah pijat refleksi dapat menurunkan tekanan darah pada penderita hipertensi. Peneliti sangat tertarik untuk meneliti "Pengaruh terapi pijat refleksi kaki terhadap tekanan darah pada penderita hipertensi primer".

\section{B. METODE DAN BAHAN}

Jenis penelitian ini adalah Quasy Eskperiment dengan desain penelitian yang digunakan adalah pre-postestcontrol one group design. Desain ini digunakan untuk membandingkan hasil intervensi dua kelompok yaitu kelompok intervensi dan kelompok kontrol, tetapi pemilihan kedua kelompok ini tidak menggunakan teknik acak.

Populasi pada penelitian ini adalah lansia yang tinggal di Panti Wredha Pajang Surakarta sebanyak 74 orang. Sampel yang dipilih pada penelitian ini adalah yang memenuhi 
kriteria inklusi yang telah ditetapkan sebagai subjek penelitian. Sampel dalam penelitian ini sejumlah 11 orang untuk masing-masing kelompok intervensi dan kelompok kontrol, sehingga jumlah keseluruhan sampel adalah 22 responden.

Variable bebas dalam penelitian ini adalah terapi pijat refleksi kaki sedangkan variabel terikatnya adalah hipertensi.Analisa dalam penelitian ini adalah untuk menganalisis hubungan dua variabel dengan menggunakan Kolmogorov Smirnov.Analisa bivariat data terhadap hasil pre test dan post test kelompok perlakuan maupun kelompok kontrol menggunakan uji Wilcoxon.Untuk menganalisa perbedaan pengaruh terapi pijat refleksi kaki terhadap tekanan darah pada penderita hipertensiprimerpada kelompok perlakuan dan kelompok kontrol sebelum dansesudah diberikan perlakuanmenggunakanuji Mann Whitney.

\section{HASIL PENELITIAN}

1. Distribusi tekanan darah sebelum dilakukan terapi pijat refleksi kaki pada kelompok perlakuan dan kelompok kontrol
Tabel Distribusi frekuensi tekanan darah sebelum diberikan perlakuan (pre test)

\begin{tabular}{|c|c|c|c|c|c|c|}
\hline \multirow{2}{*}{ No } & \multirow{2}{*}{$\begin{array}{c}\text { Ukuran } \\
\text { tekanan } \\
\text { darah } \\
(\mathrm{mmHg})\end{array}$} & \multirow{2}{*}{ Klasifikasi } & \multicolumn{2}{|c|}{$\begin{array}{c}\text { Kelompok } \\
\text { kontrol }\end{array}$} & \multicolumn{2}{|c|}{$\begin{array}{l}\text { Kelompok } \\
\text { perlakuan }\end{array}$} \\
\hline & & & $\mathbf{F}$ & $\%$ & $\mathbf{f}$ & $\%$ \\
\hline 1 & $<120$ dan $<80$ & Normal & 0 & 0 & 0 & 0 \\
\hline 2 & $\begin{array}{l}120-139 \text { dan } \\
80-89\end{array}$ & $\begin{array}{l}\text { Pre } \\
\text { Hipertensi }\end{array}$ & 0 & 0 & 0 & 0 \\
\hline 3 & $\begin{array}{l}140-159 \text { dan } \\
90-99\end{array}$ & $\begin{array}{l}\text { Hipertensi } \\
\text { derajat I }\end{array}$ & 11 & 100 & 11 & 100 \\
\hline 4 & $\begin{array}{l}>190 \text { dan } \\
>100\end{array}$ & $\begin{array}{l}\text { Hipertensi } \\
\text { derajat II }\end{array}$ & 0 & 0 & 0 & 0 \\
\hline Tot & & & 11 & 100 & 11 & 100 \\
\hline
\end{tabular}

Berdasarkan tabel menunjukkan sebelum diberi diberikan perlakuan (terapi pijat refleksi kaki), kedua kelompok rata-rata dengan hipertensi derajat I. Rata-rata tekanan darah untuk kelompok perlakuan 154,5/94,1 mmHg dan rata-rata tekanan darah untuk kelompok kontrol 153,6/94,5 mmHg.

2. Distribusi tekanan darah setelah dilakukan terapi pijat refleksi kaki pada kelompok perlakuan dan kelompok kontrol

Tabel Distribusi frekuensi berdasarkan tekanan darah sesudah diberikan perlakuan (post test)

\begin{tabular}{|c|c|c|c|c|c|c|}
\hline \multirow{2}{*}{ No } & \multirow{2}{*}{$\begin{array}{c}\text { Ukuran } \\
\text { tekanan } \\
\text { darah } \\
(\mathrm{mmHg})\end{array}$} & \multirow{2}{*}{ Klasifikasi } & \multicolumn{2}{|c|}{$\begin{array}{c}\text { Kelompok } \\
\text { kontrol }\end{array}$} & \multicolumn{2}{|c|}{$\begin{array}{l}\text { Kelompok } \\
\text { perlakuan }\end{array}$} \\
\hline & & & $\mathbf{F}$ & $\%$ & $\mathbf{f}$ & $\%$ \\
\hline 1 & $<120$ dan $<80$ & Normal & 0 & 0 & 2 & 18,2 \\
\hline 2 & $\begin{array}{l}120-139 \text { dan } \\
80-89\end{array}$ & $\begin{array}{l}\text { Pre } \\
\text { Hipertensi }\end{array}$ & 0 & 0 & 6 & 54,5 \\
\hline 3 & $\begin{array}{l}140-159 \text { dan } \\
90-99\end{array}$ & $\begin{array}{l}\text { Hipertensi } \\
\text { derajat I }\end{array}$ & 11 & 100 & 3 & 27,3 \\
\hline 4 & $\begin{array}{l}>190 \text { dan } \\
>100\end{array}$ & $\begin{array}{l}\text { Hipertensi } \\
\text { derajat II }\end{array}$ & 0 & 0 & 0 & 0 \\
\hline & & & 11 & 11 & 100 & 100 \\
\hline
\end{tabular}


GASTER Vol. XV No. 2 Agustus 2017

Sesudah diberikan terapi pijat refleksi kaki pada kelompok perlakuan 2 responden (18,2\%) dengan tekanan darah kategori normal dan 6 responden $(54,5 \%)$ tekanan darah kategori pre hipertensi dan 3 responden $(27,3 \%)$ tekanan darah kategori hipertensi derajat I. Sedangkan untuk kelompok kontrol hasil test akhir semua hipertensi derajat I. Rata-rata tekanan darah untuk kelompok perlakuan 128,6/80,0 $\mathrm{mmHg}$ dan rata-rata tekanan darah untuk kelompok kontrol 152,3/92,3 mmHg.

3. Analisa perbedaan perubahan tekanan darah pada kelompok eksperimen dan kelompok control.

a. Uji Wilcoxon

1) Pre dan Post test Untuk Kelompok Kontrol

Uji wilcoxon digunakan untuk mengetahui perbedaan tekanan darah sebelum dan sesudah diberikan perlakuan untuk masing-masing kelompok, adapun hasil uji sebagai berikut:

Tabel Hasil Uji Wilcoxon Kelompok Kontrol

\begin{tabular}{lcccl}
\hline & & \multicolumn{3}{c}{ Sistole } \\
& rerata & $\mathbf{z}_{\text {hitung }}$ & p-value & Keterangan \\
\hline Pre Test & 153,6 & 1,342 & 0,180 & Ho \\
Post Test & 152,3 & & & diterima \\
\hline
\end{tabular}

\begin{tabular}{lllll}
\hline & & \multicolumn{3}{c}{ Diastole } \\
& rerata & $\mathbf{z}_{\text {hitung }}$ & p-value & Keterangan \\
\hline Pre Test & 94,5 & 1,663 & 0,102 & $\begin{array}{l}\text { Ho } \\
\text { diterima }\end{array}$ \\
Post Test & 92,3 & & & \\
\hline
\end{tabular}

Hasil perhitungan wilcoxon untuk pengaruh terapi pijat refleksi kaki terhadap tekanan darah pada penderita hipertensi primer kelompok kontrol diperoleh nilai $z_{\text {hitung }}$ sebesar 1,342 , sedangkan $z_{\text {tabel }}$ sebesar 1,96 dap p $(0,180$ $>0,05)$, karena $z_{\text {hitung }}(1,342)$ $<z_{\text {tabel }}(1,96)$ maka Ho diterima dan Ha ditolak, artinya tidak adaperbedaan tekanan darah (Sistole) sebelum dan sesudah pada kelompok kontrol.

Hasil perhitungan wilcoxon untuk pengaruh terapi pijat refleksi kaki terhadap tekanan darah pada penderita hipertensi primerkelompok kontrol diperoleh nilai $z_{\text {hitung }}$ sebesar 1,663, sedangkan $z_{\text {tabel }}$ sebesar 1,96 dap p $(0,102>0,05)$, karena $z_{\text {hitung }}$ $(1,663)<z_{\text {tabel }}(1,96)$ maka Ho diterima dan Ha ditolak, artinya tidak adaperbedaan tekanan darah (diastole) sebelum dan sesudah pada kelompok kontrol. 
2) Pre dan Post test Untuk Kelompok Perlakuan

Uji wilcoxon digunakan untuk mengetahui perbedaan tekanan darah sebelum dan sesudah diberikan perlakuan untuk masingmasing kelompok, adapun hasil uji sebagai berikut:

Tabel Hasil Uji Wilcoxon Kelompok Perlakuan

\begin{tabular}{lllll}
\hline & \multicolumn{4}{c}{ Sistole } \\
& rerata & $\mathbf{z}_{\text {hitung }}$ & p-value & Keterangan \\
\hline Pre Test & 154,6 & 2,947 & 0,003 & Ho ditolak \\
Post Test & 128,6 & & & \\
\hline
\end{tabular}

\begin{tabular}{llllll}
\hline & & \multicolumn{3}{c}{ Diastole } \\
& rerata & $\mathbf{z}_{\text {hitung }}$ & p-value & Keterangan \\
\hline Pre Test & 94,1 & 2,274 & 0,006 & Ho ditolak \\
Post Test & 80,0 & & & \\
\hline
\end{tabular}

Hasil perhitungan wilcoxon untuk pengaruh terapi pijat refleksi kaki terhadap tekanan darah pada penderita hipertensi primer kelompok perlakuan diperoleh nilai $z_{\text {hitung }}$ sebesar 2,947, sedangkan $z_{\text {tabel }}$ sebesar 1,96 dap p $(0,003<0,05)$, karena $z_{\text {hitung }}$ $(2,947)>z_{\text {tabel }}(1,96)$ maka Ho ditolak dan Ha ditterima, artinya adaperbedaan tekanan darah (Sistole) sebelum dan sesudah pada kelompok perlakuan.
Hasil perhitungan wilcoxon untuk pengaruh terapi pijat refleksi kaki terhadap tekanan darah pada penderita hipertensi primer kelompok kontrol diperoleh nilai $z_{\text {hitung }}$ sebesar 2,274, sedangkan $z_{\text {tabel }}$ sebesar 1,96 dap p $(0,0006$ $<0,05)$, karena $z_{\text {hitung }}(2,274)>$ $z_{\text {tabel }}(1,96)$ maka Ho diterima dan Ha ditolak, artinya adaperbedaan tekanan darah (diastole) sebelum dan sesudah pada kelompok perlakuan.

\section{Uji Mann Whitney}

Tabel Hasil Uji Mann Whiney Sebelum dan sesudah Perlakuan (Sistole)

\begin{tabular}{|c|c|c|c|c|}
\hline \multirow{2}{*}{ Kelompok } & \multirow{2}{*}{ rerata } & \multicolumn{2}{|c|}{ Pre Test } & \multirow{2}{*}{ Keterangan } \\
\hline & & $\mathbf{z}_{\text {hitung }}$ & p-value & \\
\hline Pre Test & 153,6 & 0,424 & 0,672 & Ho diterima \\
\hline \multirow[t]{3}{*}{ Post Test } & 154,5 & & & \\
\hline & rerata & Pos & Test & Keteranoan \\
\hline & rerata & $\mathbf{Z}_{\text {hituno }}$ & p-value & Keterangan \\
\hline Pre Test & 153,2 & 4,101 & 0,000 & Ho ditolak \\
\hline Post Test & 128,6 & & & \\
\hline
\end{tabular}

Hasil perhitunganuji Mann Whitney untuk pengaruh terapi pijat refleksi kaki terhadap tekanan darah pada penderita hipertensi primer sebelum diberikan perlakuan(test awal) diperoleh nilai $z_{\text {hitung }}$ sebesar 0,424, sedangkan $z_{\text {hitung }}$ sebesar 1,96 dan $p$ value $(0,672>0,05)$, karena 
GASTER Vol. XV No. 2 Agustus 2017

$z_{\text {hitung }}(0,424)<z_{\text {tabel }}(1,96)$ maka Ho

diterima dan Ha ditolak, artinya tidak ada perbedaan tekanan darah (sistole) pada kelompok perlakuan dan kelompok kontrol sebelum diberikan perlakuan. Hasil ini menunjukkan kondisi awal tekanan darah sebelum perlakuan pada kedua kelompok sama artinya kedua kelompok sebelum perlakuan dengan kondisi awal setara atau asas kesetaraan terpenuhi.

Hasil perhitungan uji Mann Whitney untuk pengaruhpengaruh terapi pijat refleksi kaki terhadap tekanan darah pada penderita hipertensi primer sesudah diberikan perlakuan (post test) diperoleh nilai $z_{\text {hitung }}$ sebesar 4.101, sedangkan $z_{\text {hitung }}$ sebesar 1,96 serta $\mathrm{p}$ value $(0,000<$ $0,05)$, karena $z_{\text {hitung }}(4,101)>z_{\text {hitung }}(1,96)$ maka Ho ditolak Haditerima, artinya ada perbedaan tekanan darah (diastole) pada kelompok perlakuan dan kelompok kontrol sesudah diberikan perlakuanterapi pijat refleksi kaki.
Tabel Hasil Uji Mann Whiney Sebelum dan sesudah Perlakuan (Diastole)

\begin{tabular}{|c|c|c|c|c|}
\hline \multirow{2}{*}{ Kelompok } & \multirow{2}{*}{ rerata } & & Test & \multirow{2}{*}{ Keterangan } \\
\hline & & $\mathbf{z}_{\text {hitung }}$ & p-value & \\
\hline Kontrol & 94,5 & 0,228 & 0,820 & Ho diterima \\
\hline \multirow[t]{3}{*}{ Perlakuan } & 94,1 & & & \\
\hline & & \multicolumn{2}{|c|}{ Post Test } & \\
\hline & rerata & & p-value & Keterangan \\
\hline Kontrol & 92,3 & 3,443 & 0,001 & Ho ditolak \\
\hline Perlakuan & 80,0 & & & \\
\hline
\end{tabular}

Hasil perhitunganuji Mann Whitney untuk pengaruh terapi pijat refleksi kaki terhadap tekanan darah pada penderita hipertensi primer sebelum diberikan perlakuan(test awal) diperoleh nilai $z_{\text {hitung }}$ sebesar 0,228 , sedangkan $z_{\text {hitung }}$ sebesar 1,96 dan $p$ value $(0,228>0,05)$, karena $z_{\text {hitung }}(0,424)<z_{\text {tabel }}(1,96)$ maka Ho diterima dan Ha ditolak, artinya tidak ada perbedaan tekanan darah (diastole) pada kelompok perlakuan dan kelompok kontrol sebelum diberikan perlakuan. Hasil ini menunjukkan kondisi awal tekanan darah sebelum perlakuan pada kedua kelompok sama artinya kedua kelompok sebelum perlakuan dengan kondisi awal setara atau asas kesetaraan terpenuhi.

Hasil perhitungan uji Mann Whitney untuk pengaruh terapi pijat refleksi kaki terhadap tekanan darah pada penderita 


\section{GASTER Vol. XV No. 2 Agustus 2017}

hipertensi primer sesudah diberikan perlakuan (post test) diperoleh nilai $z_{\text {hitung }}$ sebesar 3,443, sedangkan $z_{\text {tabel }}$ sebesar 1,96 serta $p$ value $(0,001<0,05)$, karena $z_{\text {hitung }}(3,443)>z_{\text {tabel }}(1,96)$ maka Ho ditolak Haditerima, artinya ada perbedaan tekanan darah (diastole) pada kelompok perlakuan dan kelompok kontrol sesudah diberikan perlakuan terapi pijat refleksi kaki.

\section{PEMBAHASAN}

1. Tekanan Darah Sebelum dilakukan terapi pijat refleksi kaki pada kelompok perlakuan dan kelompok kontrol

Hasil penelitian menunjukkan sebelum diberikan perlakuan (senam hipertensi), rata-rata dengan hipertensi derajat I. Rata-rata tekanan darah untuk kelompok perlakuan 154,5/94,1 $\mathrm{mmHg}$ dan rata-rata tekanan darah untuk kelompok kontrol 153,6/94,5 mmHg. Hipertensi pada lansia mudah terjadi seiring bertambahnya usia. Menurut Kemenkes RI (2013) bertambahnya umur, risiko terkena hipertensi menjadi lebihbesar sehingga prevalensi hipertensi dikalangan usia lanjut cukup tinggi,yaitu sekitar 40\%, dengan kematian sekitar diatas usia
65 tahun (Kemenkes,2013). Nugroho (2012)menyebutkan bahwa individu berumur55 tahun memiliki $90 \%$ risiko untuk mengalami hipertensi. Menurut Pudiastuti (2013) memaparkan bahwa tekanan sistolik terus meningkatsampai usia 80 tahun dan tekanan diastolik terus meningkat sampai usia55-60 tahun, kemudian berkurang secara perlahan atau bahkan menurun drastis.

Pada lansia kejadian hipertensi merupakan hal yang wajar meningkat bertambahnya usia. Rindang (2015) menjelaskan seseorang bertambah tua maka ia juga mengalami perubahan fisiologis, misalnya penurunan elastisitas arteri dan juga adanya kekakuan pembuluh darah, hal ini yang menyebabkan risiko hipertensi akan naik dengan bertambahnya umur. Adanya banyak hal yang bisa dilakukan untuk menurunkan risiko hipertensi pada lansia. Lansia harus diperhatikan asupan makanan serta aktivitas fisiknya.

2. Tekanan Darah Sesudah dilakukan terapi pijat refleksi kaki pada kelompok perlakuan dan kelompok kontrol

Tekanan darah sesudah perlakuan, yaitu dengan menggunakan terapi pijat 
refleksi kaki pada kelompok perlakuan mengalami penurunan tekanan darah yang signifikan. Pada kondisi awal dengan ratarata $154,6 / 94,1 \mathrm{mmHg}$ menurun menjadi 128,6/80,0 mmHg. Sedangkan pada kelompok kontrol 153,6/94,5 mmHg hanya turun sedikit menjadi menjadi 152,3/92,3 mmHg. Hal ini menggambarkan pada kelompok yang diberikan terapi pijat refleksi kaki mengalami penurunan yang cukup tajam dibandingkan dengan kelompok kontrol.

Pada kelompok yang diberikan terapi pijat refleksi kaki mengalami penurunan yang lebih tajam dibandingkan dengan kelompok yang tidak diberikan terapi. Setelah diberikan terapi pijat kaki dari hipertensi tingkat 1 rata-rata turun menjadi pre hipertensi dan ada 2 responden yang normal. Sedangkan pada kelompok kontrol dari hipertensi tingkat satu setelah pengukuran akhir tetap hipertensi tingkat I.

Hasil penelitian tersebut menunjukkan efektivitas penurunan tekanan darah yang cukup signifikan akibat diberikan diberikan terapi pijat kaki. Hal ini seperti yang dijelaskan oleh (Wahyuni, 2014)terapi pijat kaki melancarkan sirkulasi darah di dalam seluruh tubuh, menjaga kesehatan agar tetap prima, membantu mengurangi rasa sakit dan kelelahan, melancarkan produksi hormon endorfin yang berfungsi untuk rileksasi tubuh sehingga tekanan darah menurun. Hal tersebut juga dijelaskan oleh Dalimartha (2008) teknik pemijatan berdampak terhadaplancarnya sirkulasi aliran darah,menyeimbangkan aliran energi di dalamtubuh serta mengendurkan keteganganotot. Meskipun teknik pemijatan tidakakan berdampak banyak pada penderitahipertensi berat, tetapi beberapa penelitiantelah membuktikan bahwa massase dapatmenurunkan tekanan darah pada penderitahipertensi ringan dan sedang. Sedangkan penelitian oleh Zunaidi, et al (2014) terdapat perbedaan antara terapi pijat refleksi dan massage kaki terhadap penurunan tekanan dan pada penelitian ini memberikan rekomendasi terapi pijat refleksi sebagai salah satu terapi komplementer mampu di aplikasikan perawat dalam menurunkantekanan darah pada penderita hipertensi.

Penelitian Chanif(2016) menyebutkan bahwa terdapat perbedaan yang signifikan 


\section{GASTER Vol. XV No. 2 Agustus 2017}

tekanandarah sistolik, diastolik dan MAP sebelum dan setelah perlakuan terapi pijat refleksi kaki. Sedangkan penelitian Rindang (2015) menyebutkan bahwa terdapat perbedaan antara tekanan darah kelompok eksperimendan kelompok kontrol.

3. PengaruhTerapi Pijat Refleksi Kaki Terhadap Tekanan Darah pada Penderita Hipertensi Primerdi Panti Wreda Pajang Surakarta

Hasil penelitian menunjukkan terapi pijat refleksi kaki efektif menurunkan tekanan darah pada lansia. Hasil penelitian setelah dilakukan refleksi kaki tekanan darah lansia mengalami penurunan yang tajam.Aktivitas fisik sangat penting untuk meningkat kesehatan lansia, salah satunya adalah terapi refleksi kaki. Refleksi kaki tidak hanya dengan pijat tetapi juga dapat dilakukan dengan Olah raga rutin berjalan telanjang kaki. Menurut Nugroho (2012) olah raga rutin berjalan telanjang kaki, secara otomatis titik refleksi pada kaki mendapat tekanan (pijatan). Hal itu sangat baik untuk kesehatan seluruh tubuh. Lebih baik lagi jika dilakukan di sarana refleksi kaki yang disediakan. Rindang (2015) mengemukakan bahwa refleksi pijat kaki cukup efektif memberikan rangsangan relaksasi yangmampu memperlancar aliran darah dancairan tubuh pada bagianbagian tubuhyang berhubungan dengan titik syaraf kakiyang dipijat.

Pijat melancarkanperedaran darah dan aliran getah bening.Efek langsung yang bersifat mekanis daritekanan secara berirama dan gerakan-gerakanyang digunakan dalam pijat secaradramatis meningkatkan tingkat alirandarah. Rangsangan yang ditimbulkanterhadap reseptor saraf jugamengakibatkan pembuluh darah melebarsecara refleks sehingga melancarkan alirandarah yang sangat berpengaruh bagikesehatan.

Hasil uji statistik baik sistole maupun diastole menunjukkan adanya pengaruh signifikan terapi pijat refleksi kaki terhadap penuruna tekanan darah pada lansia. Pada kelompok perlakuan sebelum dan sesudah terdapat perbedaan yang signifikan $(\mathrm{p}<$ 0,005) sedangkan pada kelompok kontrol tidak ada perbedaan yang signifikan $(\mathrm{p}>$ 0,05). Perbandingan keduanya dapat 
dilihat dari nilai rata-rata hasil akhir dari kelompok perlakuan (terapi pijat refleksi kaki) yaitu sebesar $128,6 / 80,0 \mathrm{mmHg}$, sedangkan kelompok kontrol rata-rata hasil test akhir 152,3/92,3 mmHg. Hal ini membuktikan terapi pijat refleksi kaki signifikan berpengaruh positif terhadap penurunan tekanan darah pada lansia.

Efektivitas penurunan tekanan darah sebagai dampak dari pemberian terapi pijat refleksi juga didukung oleh penelitian yang dilakukan oleh Zunaidi, et al (2014) yang melakukan penelitian pengaruh pijat refleksi terhadap tekanan darah pada penderita hipertensi di Klinik Sehat Hasta Therapetika Tugurejo Semarang dengan hasil terdapat perbedaan antara terapi pijat refleksi dan massage kaki terhadap penurunan tekanandarah pada responden dengan nilai tekanan darah sistole $p$ value 0.033 dan diastol $p$ value 0.017. sedangkan penelitian lain yang mendukung adalah penelitian Rindang, et al (2015) terdapat pengaruh terapi pijatrefleksi kakiterhadap tekanan darah padapenderita hipertensi. Hasil penelitian ini juga membuktikan adanya perbedaan antara mean post testantara tekanan darah kelompok eksperimendan kelompok kontrol.

\section{E. SIMPULAN DAN SARAN}

Pada kelompok kontrol sebelum dilakukan perlakuan, sebagian besar dengan hipertensi derajat I) dan setelah dilakukan perlakuansebagian besar dengan hipertensi derajat I. Rata-rata sebelum sebesar 153,6/94,5 mmHg turun menjadi 152,3/92,3 mmHg.

Pada kelompok perlakuan sebelum dilakukan perlakuan, sebagian besar dengan hipertensi derajat Idan setelah dilakukan perlakuan sebagian besar dengan hipertensi tingkat ringan (derajat I) dan setelah diberi perlakuan terapi pijat refleksi kaki sebagian besar turun menjadi pre hipertensi. Rata-rata sebelum rata-rata $154,5 / 94,1 \mathrm{mmHg}$ menurun menjadi 128,6/80,0 $\mathrm{mmHg}$.

Ada perbedaan signifikan tekanan darah sebelum dan sesudah perlakuan pada kelompok terapi pijat refleksi kaki. Tidak ada perbedaan signifikan tekanan darah sebelum dan sesudah perlakuan pada kelompok kontrol. Ada pengaruh signifikan pemberian terapi pijat refleksi kakiterhadap tekanan darah pada penderita hipertensi primer.Masih 


\section{GASTER Vol. XV No. 2 Agustus 2017}

diperlukan penelitian lebih lanjut tentang terapi pijat refleksi kaki sebagai salah satu terapi komplementer pada penderita hipertensi. Terapi pijat refleksi sebagai salah satu terapi komplementer diharapkan mampu untuk diaplikasikan perawat dalam menurunkan tekanan darah pada penderita hipertensi

\section{DAFTAR PUSTAKA}

Anwar, R. (2014). Konsumsi Buah Dan Sayur Serta Konsumsi Susu Sebagai Faktor Risiko Terjadinya Hipertensi DI Puskesmas S. Parman Kota Banjarmasin. Jurnal Skala Kesehatan Volume 5 No 1 tahun 2014

Ardiansyah, M. (2012). Medikal Bedah Untuk Mahasiswa. Jogjakarta : DIVA PressBaradero, M. Dayrit, M.W. \& Siswadi, Y. Klien gangguan kardiovaskuler seri asuhan keperawatan. Jakarta : EGC. 2008

Chanif, Khoiriyah, 2016. Penurunan tekanan darah pada pasien hipertensi berbasis Terapi pijat refleksi kaki.

Dalimartha, S.Purnama, B.T Sutarina, N. Mahendra, B. \& darmawan,, R. Care your self hipertensi. Depok : Penebar Plus. 2008

Finansari, T. Y., Setyawan, D.,Meikawati, W.,(2014). Perebedaan terapi musik klasik dan Musik yang disukai terhadap tekanan darah pada pasien Hipertensi Di RSUD DR. H.soewondo Kendal

Hasneli, Y. Oktaviah, D, Darmilis. TEMPURA (Coconut Shells) as a foot eercise therapy on blood circulation and sensitivity foot for diabetic patients. RIAU International Nursing Conference (hal 58). Pekanbaru : School of Nursing University of Riau.

Herlambang.(2013). Menaklukan hipertensi dan diabetes.Jagakarsa : PT. suka buku.

Kemenkes RI. Profil Kesehatan Indonesia Tahun 2013. Jakarta., Kementrian Kesehatan Republik Indonesia. 
Kowalski, RE. Terapi hipertensi : program 8 minggu menurunkan tekanan darah tinggi dan mengurangi resiko serangan jantung dan stroke secara alami. Bandung : Penerbit Qanita. 2010

Kumar, V. Pijat refleksi. Jakarta : BIP Kelompok Gramedia. 2009

Nugroho,, I. A. Asrin, \& Sarwono. 2012. Efektivitas pijat refleksi kaki dan hipnoterapi terhadap penurunan tekanan darah pada pasien hipertensi. Jurnal Ilmiah kesehatan Keperawatan, 8(2). Diperoleh tanggal 27 Januari 2017 dari http:/www.academia.edu/373947Jstikesmuhgogdl-irmawand-13652-hal 57-3

Nursalam. (2016). Metodologi Penelitian Ilmu Keperawatan. Jakarta : Salemba Medika.

Provil Kesehatan Jawa Tengah.(2015). Profil kesehatan jawa tengah tahun 2015. (online),(http:// www.dinkesjatengprov,go.id/). Diakes tanggal 12 maret 2017

Pudiastuti, R.D. Penyakit-penyakit mematikan. Yogyakarta : Nuha Medika. 2013.

Rindang Azhari Rezky, R.A,dkk. 2015. Pengaruh terapi pijat refleksi kaki Terhadap tekanan darah pada Penderita hipertensi primer. JOM Vol. 2 No. 2, Oktober 2015

Riskesdas, Badan penelitian dan pengembangan kesehatan kementrian kesehatan RI tahun 2013. Diperoleh tanggal 10 Januari 2017 dari http:www.riskesdas.litbang.depkes.go.id/ download/laporan riskesdas.2011.pdf

Sulistyarini, T. (2015). Musik Klasik Lebih Efektif Dibandingkan Relaksasi Nafas Dalam Terhadap Penurunan Tekanan Darah. Jurnal Penelitian Keperawatan. volume 1. No 1 Januari 2015

Susilo, Y \& Wulandari, A. Cara Jitu Mengatasi Hipertensi. Andi : Yogyakarta. 2011

Tarigan. Sehat dengan terapi pijat. Diperoleh pada tanggal 27 Januari 2017 dari http://www. mediaindonesia.com

Triyanto, E. (2014). Pelayanan Keperawatan bagi Penderita Hipertensi secara Terpadu. Yogyakarta : Graha Ilmu 


\section{GASTER Vol. XV No. 2 Agustus 2017}

Wahyuni, S. Pengaruh massage ekstremitas dengan aroma terapi lavender terhadap penurunan tekanan darah pada lansia di Kalurahan Grendeng Purwokerto. Universitas jendral Soedirman : Purwokerto. 2014. Diperoleh pada tanggal 27 Januari 2017 dari http:// keperawatan.unsoed.ac.idsitesdefault/files/INDAH/\%20SETYA\%WAHYUNI.pdf

Wahyuni, S. Pijat refleksi untuk kesehatan. Jakarta Timur : Dunia Sehat. 2014

WHO, A Global Brief Hypertension : Silent Killer, Global Public Health Disease, Switerland WHO Press. 2013

Wijaya, A.S. \& Putri, Y.M. (2013). Keperawatan Medikal Bedah. Yogyakarta : Nuha Medika

Zunaidi, Ahmad, dkk. 2014. Pengaruh Pijat Refleksi Terhadap Tekanan Darah Pada Penderita Hipertensi Di Klinik Sehat Hasta Therapetika Tugurejo Semarang.Prosiding Konferensi Nasional II Ppni Jawa Tengah 2014.

146 Pengaruh Terapi Pijat Refleksi ... 